\title{
Implementation of Trauma-Informed Care in a Housing First Program for Survivors of Intimate Partner Violence: A Case Study
}

\author{
Allison Ward-Lasher \\ Jill Messing \\ Jillian Stein-Seroussi
}

\begin{abstract}
The intersection of trauma with the need for safe, stable, sustainable, and longterm housing is important when working with survivors of intimate partner violence (IPV). $I P V$ advocacy agencies are advised to use a trauma-informed approach to help practitioners understand the impact of IPV on individuals. Housing First, a model addressing homelessness that provides permanent housing without preconditions, has been found to increase housing stability for survivors of IPV. Thus, we used a case study approach to examine how practitioners and administrators implement trauma-informed care in a Housing First program for IPV survivors. Trauma-informed care principles and the Housing First model were found to be complementary. The majority of clients in this program retained housing up to 3-months after services ended and increased their safety and knowledge of domestic violence. Combining Housing First with trauma-informed care may increase success for survivors of IPV.
\end{abstract}

Keywords: Housing First; intimate partner violence; trauma-informed care

It is estimated that $35 \%$ of women have been abused by an intimate partner and approximately $24 \%$ have experienced severe physical intimate partner violence (IPV) in their lifetime (Black et al., 2011). Survivors of IPV commonly report experiencing psychological symptoms associated with trauma, such as depression, anxiety, fear, and PTSD symptoms (i.e., nightmares, avoidance, and dissociation; Black et al., 2011). Survivors of IPV have a multitude of needs (Allen, Bybee, \& Sullivan, 2004), though housing has been reported by survivors as one of the most needed services upon exiting a violent relationship (Dichter \& Rhodes, 2011). This is because IPV is associated with housing instability (Baker, Billhardt, Warren, Rollins, \& Glass, 2010; Pavao, Alvarez, Baumrind, Induni, \& Kimerling, 2007), which leads to homelessness (Baker et al., 2010). Women who exit violent relationships are at risk for housing instability due to economic dependence in their relationship (Postmus, Plummer, McMahon, Murshid, \& Kim, 2012), lack of employment, economic disparities, and barriers to renting, such as poor credit or a criminal record (Baker et al., 2010). Thus, homelessness and housing instability for female survivors of IPV and their children are a primary concern among service providers (Macy, Giattina, Montijo, \& Ermentrout, 2010).

The intersection of trauma and housing stability among women exiting (or seeking respite from) violent relationships is the focus of this research. Organizations providing services to survivors of IPV are encouraged to use a trauma-informed approach as a bestpractice (Wilson, Fauci, \& Goodman, 2015). There is evidence to suggest that a Housing

Allison Ward-Lasher MSW is a Doctoral Candidate, School of Social Work, Arizona State University Phoenix, AZ, 85004. Jill Teresa Messing, PhD, MSW is an Associate Professor, School of Social Work, Arizona State University, Phoenix, AZ 85004. Jillian Stein-Seroussi, is a Master's Student, School of Social Work, University of North Carolina at Chapel Hill, Carrboro, NC 27510. 
First model may be a successful approach to address the housing needs of survivors of IPV who are seeking services from domestic violence agencies (Mbilinyi, 2015). Thus, the goal of this case study is to describe and examine the intersection of a trauma-informed care approach and a Housing First model within a single domestic violence program in the Southwest U.S.

\section{IPV \& Housing Instability}

A woman's decision to leave her abusive partner is associated with more severe and frequent violence and is also a risk factor for homicide, making this a dangerous time in a survivor's life (Campbell, Glass, Sharps, Laughon, \& Bloom, 2007). Traditionally, one of the primary interventions for survivors of IPV is the provision of emergency shelter. Shelters may reduce subsequent moderate and severe violence (Messing, O'Sullivan, Cavanaugh, \& Campbell, 2016), providing women who leave an abusive partner a safe, temporary, and short-term place to stay where they can access IPV-related services, such as legal advocacy, education, and counseling (Baker et al., 2010). But all too often, women exiting emergency shelters are not transitioning to permanent housing (Sullivan, Basta, Tan, \& Davidson, 1992). Requirements of longer-term transitional or permanent housing programs make it difficult for women with co-occurring issues, such as substance abuse or mental health diagnoses, to access these services (Baker et al., 2010).

An innovative approach to addressing the housing needs of survivors of IPV is a Housing First model that advocates for individuals who are experiencing homelessness to receive permanent housing in the community without preconditions, such as substance use or mental health treatment (Padgett, Henwood, \& Tsemberis, 2015). The basic tenet of the Housing First paradigm is that clients' basic needs must be met (i.e., stable housing) before they can then focus on secondary needs (i.e., recovery; Schiff \& Schiff, 2014). Once permanent housing is attained, supportive services are offered that clients can choose to access, but are not required to stay in the program (Padgett et al., 2015). Although Housing First has been successful as a model to address homelessness (Montgomery, Hill, Kane, \& Culhane, 2013; Patterson et al., 2013), it is a relatively new approach to addressing the housing needs of survivors of IPV. The Washington State Coalition Against Domestic Violence implemented a Housing First approach in several agencies statewide (Mbilinyi, 2015). Upon evaluation, they found that the vast majority of survivors were able to achieve and retain permanent housing, even with the significant barriers to housing clients faced (i.e., unemployment, criminal records; Mbilinyi, 2015). Thus, a Housing First model may be a successful intervention for IPV survivors and, given the trauma caused by abuse, there is a need to elucidate the relationship between trauma-informed care and Housing First in an IPV setting.

\section{Trauma-Informed Care \& Housing First}

The specific components of a trauma-informed approach in IPV intervention (Elliott, Bjelajac, Fallot, Markoff, \& Reed, 2005; Wilson et al., 2015) have been conceptualized as six principles: emotional safety, client choice, domestic violence education, relationship development, using an intersectional approach, and a strengths-based perspective (Wilson et al., 2015). First, attending to a client's emotional safety is an important component of a 
trauma-informed approach. Programs that are community-based and have flexible funding, such as Housing First, give survivors greater control over their environment by choosing where they live within the community; this may make them feel safe and minimize retraumatization.

IPV shelter services have been criticized for having strict rules (Arnold \& Ake, 2013; McDermott \& Garofalo, 2004), such as curfew and chores that can emulate the control of an abusive partner and limit client choice (Messing, Ward-Lasher, Thaller, \& BagwellGray, 2015; Stark, 2007). Client choice is a component of trauma-informed care in IPV settings, and Housing First models (with less restrictive rules and preconditions) have been found to increase clients' choice when compared to traditional interventions (Tsemberis, Gulcur, \& Nakae, 2004). Another component of a trauma-informed care model is relationship development (Strand, Hansen, \& Courtney, 2013; Wilson et al., 2015). Relationships between survivors and staff members should be collaborative (Elliott et al., 2005) and supportive (Wilson et al., 2015), which has been identified as a key component in a Housing First approach to survivors of IPV (Mbilinyi, 2015).

Domestic violence education is integral to strengthening coping skills within a traumainformed care model (Elliott et al., 2005; Wilson et al., 2015). Housing First complements this principle by meeting the housing needs of clients first, leaving them better able to focus on understanding IPV and developing coping skills (Mbilinyi, 2015). An intersectional approach to working with clients through culturally competent staff is another main component of trauma-informed services (Elliott et al., 2005; Wilson et al., 2015). Ethnic minority, immigrant, or lesbian women may not be comfortable seeking services from domestic violence shelters because of language barriers, the stigma associated with seeking services, or fear of discrimination (Baker et al., 2010). Therefore, community-based services may be a more comfortable option for women with marginalized identities. Within IPV intervention, Housing First models have been identified as culturally responsive due to the survivor-defined nature of the intervention (Mbilinyi, 2015). The final component of trauma-informed care is a strengths-based perspective that identifies client strengths and builds on them (Elliott et al., 2005; Wilson et al., 2015). The flexibility of a Housing First model allows practitioners to safety plan, resource creatively, and empower survivors using their existing strengths (Mbilinyi, 2015). Trauma-informed domestic violence programs and the Housing First model have the potential to support IPV survivors through the interconnection of the six principles within an evidence based practice framework (Strand et al., 2013).

\section{Study Aims}

Among survivors of intimate partner violence, the need for trauma-informed care and housing overlap. Yet, to our knowledge, there is no research to date specifically examining the intersection of trauma-informed care and Housing First models in a domestic violence agency. Thus, we aim to answer the question: How is trauma-informed care implemented within a Housing First model in a single domestic violence agency? 


\section{Method}

Since the intersection of Housing First and trauma-informed care in IPV interventions is understudied, we used a case study research design and methodology (Yin, 2014). A case study is an ideal method of research when the purpose is to examine "a contemporary phenomenon in depth" (Yin, 2014, pp. 16). The unit of analysis in this research is one agency in the Southwestern U.S. that provides trauma-informed housing stabilization services for survivors of IPV using a Housing First model. In case study research, it is best to use multiple forms of data (Yin, 2014). Therefore, in 2015, we conducted qualitative interviews with agency staff, observed a staff meeting, and analyzed secondary client outcome data provided by the agency.

\section{Study Site \& Client Description}

In 2014 and 2015, the agency served a total of 226 individuals (91 adults, 135 children) in their Housing First program. Approximately half of the clients in the program were Hispanic/Latino/a $(n=114), 20 \%$ were Caucasian $(n=45), 11 \%$ were African American/Black $(n=25), 10 \%$ were unknown $(n=22)$, and $9 \%$ were categorized as other ( $n=20)$. In 2014 and 2015, 135 clients "exited" the program. Of those, 111 were renting their own place, 20 were staying or living with a friend/family member, 3 owned a residence, and 1 was unknown. Based on the agency's survey data, 86-100\% of clients were satisfied with the services that they received at the agency (average agreement rate of 97.1\%). In 2014 and 2015, the average length of stay in the program was 11.3 months and 9.1 months, respectively. In general, the length of stay in the Housing First program is 9 months. However, the agency recognizes that some clients may need more time to reach self-sufficiency due to significant barriers (i.e., documentation status) and will adjust clients' length of stay in the program on a case-by-case basis.

\section{Participants}

The participants in this study were seven employees of the agency (administrators $n=3$, practitioners $n=4$ ) who work directly with the Housing First program. All participants were female. On average, participants had slightly more than 4 years of experience working with domestic violence survivors and just under 4 years of that experience was with this agency. The education level of participants varied from high school completion to graduate degree. Two of the administrators held Master's degrees while one had a Bachelor's degree. Two practitioners had Master's degrees, one had a Bachelor's degree, and the other had completed high school.

\section{Data Sources}

Data from study participants were collected through interviews and direct observation of a staff meeting. Qualitative interviews were conducted using a semi-structured interview guide, were audio recorded, and on average 1-2 hours long. For administrators, questions focused on the program's mission, goals, and client outcomes. The interview guide for practitioners focused on examining their direct practice with clients of the agency (see Table 1 for sample questions from the interview guide). The qualitative interview audio 
files were first transcribed by the research team then transferred to Dedoose (2016) for analysis. Codes were developed based on the study aims and propositions (Yin, 2014). Each transcript was coded independently by two members of the research team for interrater reliability. One member of the research team attended an agency staff meeting and took detailed notes.

Table 1. Sample Interview Questions

\begin{tabular}{|c|c|}
\hline Administrators & $\begin{array}{r}\text { Practitioners } \\
\end{array}$ \\
\hline $\begin{array}{l}\text { - What is the mission of the program? } \\
\text { - What is the philosophy or theoretical } \\
\text { framework? } \\
\text { - What is a typical client for the agency? } \\
\text { locating housing for a client? }\end{array}$ & $\begin{array}{l}\text { - Can you describe your work here at the } \\
\text { agency? } \\
\text { - Can you tell me a success story? } \\
\text { - Can you tell me about a time where these } \\
\text { services were not helpful? } \\
\text { - What considerations are made when } \\
\text { locating housing for a client? }\end{array}$ \\
\hline
\end{tabular}

Data from the agency's clients was pre-existing, de-identified data collected by the agency between 2014 and 2015. These data consisted of basic information including age, gender, ethnicity, and exit destination. The agency's client data also consisted of responses to a quarterly survey administered by the agency that included statements related to client knowledge of domestic violence, client self-esteem, client safety, knowledge of community resources, and client perception of the program (see Table 2 for sample agency survey items). Client responses were reported as "agree" or "disagree" by the agency. The agency provided us with the total number of surveys completed and the survey responses tallied by quarter. In order to assess client outcomes using these pre-existing agency data, we averaged the percent of client agreement to each statement across quarters. The agency reported 67 responses to the survey, but could not provide information about whether clients responded multiple times or the response rate.

Table 2. Survey Distributed by the Agency: Sample Items

\section{Domestic Violence Education/Knowledge}

- My child(ren) better understand domestic violence since receiving services

- My knowledge about DV and its effects on my life has increased since receiving services

- I better understand how domestic violence has affected my child(ren) since receiving services

\section{Self-esteem/Self-efficacy}

- My child(ren) has an increased sense of self-esteem since receiving services

- I feel that I am (re)gaining control of my life after receiving services

- I feel more self-sufficient after receiving services

\section{Safety}

- My child(ren) better understand how to stay safe since receiving services

- My safety has improved since receiving services

- My knowledge of how to plan for my safety has increased since receiving services 


\section{Community Resources}

- My knowledge of how to access short and long term resources available to meet my needs has increased

- My knowledge of community resources and services has increased since receiving services

\section{Program}

- I am satisfied with the services my child(ren) received

- I feel that I met at least one goal on my case plan

- I am satisfied with the services I have received at [the agency]

\section{Results}

The results are organized to primarily highlight the data collected during qualitative interviews with participants (agency practitioners and administrators), while observational data and data from the survey distributed by the agency to their clients are supplemental.

\section{Connecting Trauma and Housing}

Participants recognized that, in order for their Housing First program to be traumainformed, they need to connect trauma with housing stabilization services and interventions. One administrator stated, "All of our services are provided with the knowledge that trauma impacts people's lives and thus their behavior." The connection between trauma and housing was further described: “....another component that plays into the process of looking for permanent housing is also working through their trauma of what housing has looked like in the past and what housing will look like once they're on their own..." Specifically, participants connected housing and trauma by assessing physical and emotional safety and understanding how housing can "trigger" survivors of IPV, or lead to a memory or flashback of their trauma. Practitioners discussed the location of client housing in relation to where their abuser and/or his family live; they also consider characteristics of the neighborhood that may provide emotional and physical safety. For example, one practitioner reported:

So, things that we look at are: What area of town is safe?...If you go to the grocery store, are you going to run into him, or family or friends... We look at do they have access to a bus?...Is it going to be a mile walk without street lights that they have to come home to at night?

Because of the need for emotional and physical safety, the agency needs a wide network of landlords in all areas of town in order to accommodate a survivor's location preference. The vast majority (91-100\%) of clients agreed that their safety had improved since receiving services (average agreement rate of $98.9 \%$ ).

Housing can also create feelings of isolation or be a reminder of financial abuse based on a survivor's experience of IPV. Thus, practitioners need to assess for things such as:

Was [abuser] withholding the food stamps or money to get food? Or was it that he was like 'Let's just go shopping and buy everything' at the beginning of the month and then at the end of the month you guys have nothing. 
With the knowledge that housing and associated housing issues can be triggering, practitioners must prepare and assist clients in learning new coping strategies.

\section{Trauma-Informed Interventions}

All participants said that, to be trauma informed, it was necessary to provide emotional support to survivors: “...provid[ing] the emotional support and [domestic violence] education to help them continue on their healing process." Practitioners dedicated specific counseling sessions to "processing abuse...[and] their emotions around it and offering support around that." One practitioner discussed the importance of survivors processing the loss that is associated with their experience: "Being able to grieve the loss of the relationship and... live with those feelings and not feeling guilt and not wanting to return..." Some practitioners described their use of role-play as a way to provide support and prepare clients for a time when they may need to engage with their abusers. One practitioner stated that she uses "emotional safety planning where they have to [role play] a conversation with their abusers or exchange an email and what that could look like." The agency also provides specific social work interventions with a trauma-informed approach, such as motivational interviewing, and refers clients to other community agencies that provide trauma-specific interventions.

The majority of participants talked about the need to educate survivors about how trauma impacts their emotions and behavior. Both administrators and practitioners said that domestic violence education was crucial to understanding the triggers associated with trauma and housing, and is an important part of helping survivors develop coping skills. One administrator discussed an "emergency self-care plan" the agency uses to assist with this process:

[It] identif[ies] all of the things that might become triggering for them and identif[ies] how that looks, how that might play out, how that has played out in the past, to be able to identify 'right now I'm in a crisis', 'right now I'm experiencing

a panic attack' and then being able to identify the way that they can self-soothe.

It is also important to incorporate interventions that include education for the entire family about the impact of IPV. Practitioners discussed helping survivors process their children's behavior and assisting them in differentiating when the behavior is associated with trauma and when the behavior is "just age-appropriate." According to the client surveys administered by the agency, 91-100\% of survivors agreed that their knowledge of domestic violence increased since receiving services (average rate of agreement 98.9\%). However, there was a wider range of agreement when assessing their children's knowledge of domestic violence (50-100\%; average rate of agreement $92.9 \%$ ).

\section{Engagement}

Engagement with the staff and the program is an integral aspect of relationship development within the trauma-informed care principles. An administrator defined engagement as: "[a] therapeutic concept that it's the relationship that gets you to the outcomes. So [practitioners] focus [on] the relationship that they build with the [client]." Every participant (administrators and practitioners) discussed the concept of client 
engagement in the program as necessary to success. One administrator illustrated how trauma can impact a client's willingness to engage with a practitioner: "So, sometimes keeping people at a distance keeps [the client] safe, because [they] don't hurt. And so, [they] might not want to necessarily engage when [they're] not feeling quite safe." On the other hand, this initial skepticism may indicate healthy boundaries, a component that is taught in this trauma-informed care model. Open and honest communication between the client and the practitioner was identified by all participants as a key aspect of engagement and relationship development. Practitioners identified engagement as a partnership between them and the client and pointed out that facilitating this level of engagement "start[s] with me...being honest to them." In a trauma-informed care model, it is important for practitioners to remember how trauma impacts a client's willingness to engage:

In a lot of situations, they couldn't talk to anybody, because they were isolated. Or if they said something to their abuser, like expressed how they felt or their thoughts, it could lead to them getting further abused or talked down to or whatever.

According to practitioners and administrators, engagement with clients (or the relationship between clients and practitioners) directly impacts client outcomes. One administrator said that engagement is "...being authentic, genuine, honest, loving, caring, compassionate, unconditional...those are the, like, core pieces of the model that I think is where [clients] find the success." Building relationships with staff is seen as a core component of traumainformed intervention:

To be able to build that relationship with the [client] to feel trust, to explore reasons why they're doing certain things or feeling certain things. Because if you don't have that good relationship with somebody and that ability to have open and honest conversations and to look at those deep-rooted issues of domestic violence and how that's playing out in their life, those barriers will continue to overcome, no matter how many resources, housing, subsidies you throw at them.

Engagement with the program is needed from clients, staff, and administrators for success. Practitioners discussed the importance of their own engagement in open and honest communication with the program, their peers, and their supervisors. This was described as facilitating a culture where it is acceptable for practitioners to ask for help: "that open and honest communication, like being able to be honest and say like "I am burnt out right now. I need help. I need a different perspective on this situation."”

Engagement also extends to family and friends. Survivors commonly begin to evaluate their relationships with others based on their abuse experience and what they learn in the program: "We often hear [clients] start thinking about it very differently in the sense of like 'I recognize this person did this and I recognize that it looked like something that I've experienced in the past." From a trauma-informed approach, the staff conceptualizes this as an opportunity:

... to discuss the logistics of that relationship and whether it's healthy or not and talk about what... [abuse] looked like in the past and what they're doing right now 
and how hard they're working right now in thinking about what they want to do for their future.

\section{Being a Trauma-Informed Agency}

This agency stressed that being trauma-informed includes providing training and selfcare for practitioners. Administrators discussed training their staff on how trauma can impact a survivor's participation in the program and their decision making:

A [client] may not be able to follow through with something, an interview or something they said they were going to work on, and how can we ... look at and pay attention to the reality that there might be something underlying that, rather than 'I just don't want to do it' or 'I just didn't have time'.

One of the primary features of a Housing First model is the exclusion of preconditions for enrollment into the housing program (i.e., substance use, mental health treatment). Thus, it is important that staff is educated about the connection between trauma, substance misuse, and IPV:

In terms of substance abuse, our philosophy here at [the agency] is that we understand that many people cope with their abuse through substance abuse to help numb out the feelings, to help escape those feelings. And it could be part of their abuse that their abuser made them use in order to stay weak, you know, not clear-minded.

Employee self-care is a major part of being a trauma-informed agency. One administrator said, “... to be a trauma-informed organization, like you have to take care of your staff the way you take care of your clients, because what's good for them is good for us." Each practitioner spoke about the agency encouraging time-off and taking care of themselves individually and as a group. This was exemplified by one practitioner:

Our supervisors' are super supportive about whatever it is we need, whether it's a day or days...or an afternoon. And what we usually try to do at least once a month...is what we call a Restorative Meeting, when we'll ...meditation or we'll do ... self-care activities ... So those are always really helpful.

This was evident within the agency culture. For example, during the staff meeting that was observed, "Self-care was encouraged for both [clients] and staff."

\section{Discussion}

The intersection of trauma-informed care and Housing First has the potential to improve the lives of IPV survivors who are at risk for homelessness. Considerations of safety and trauma are an integral component of a program that locates permanent housing for IPV survivors. One of the main findings of this study was the need for emotional safety when locating housing for a survivor of IPV. Any practitioner assisting survivors of IPV with obtaining permanent housing from a trauma-informed perspective needs to ensure that the environment is both physically and emotionally safe. A Housing First program can create this safe space by asking clients where in the community they would feel the safest. 
Survivors of IPV have reported both costs and benefits to seeking safety (Thomas, Goodman, \& Putnins, 2015). A housing risk assessment may be a useful intervention to assess a client's level of risk for further violence, allowing a survivor to make an informed decision about available housing options. Current housing assessment tools, such as the Service Prioritization Decision Assistance Tool (SPDAT)/Vulnerability Index - Service Prioritization Decision Assistance Tool (VI-SPDAT) help agencies determine individual's or family's eligibility and urgency for housing assistance (OrgCode Consulting, 2017), but have not been identified as helpful tools for assessing risk for further violence in relation to housing needs. Other tools commonly used by housing agencies are self-sufficiency matrices (SSMs), which have a dual purpose of assisting practitioners with goal-setting based on their clients' needs and evaluating progress in goal-attainment (Richmond et al., 2015). SSMs often include a domain to assess family relations and/or functioning (i.e., Culhane, Gross, Parker, Poppe, \& Sykes, 2008), however, there are few that are evidencebased (Richmond et al., 2015). The use of risk assessment, such as the Danger Assessment, within an evidence based practice framework to assess a client's level of risk for revictimization or lethality (Campbell, 2003; Messing \& Thaller, 2015) could be used when safety planning and considering various available housing options, while taking into account her risk.

Domestic violence practitioners working in Housing First programs should consider that trauma related to a prior history of financial abuse may be triggered by financial assistance during stabilization in independent housing. Survivors of IPV commonly experience financial abuse such as their partner withholding money or giving them a weekly allowance (Postmus et al., 2012). Practitioners in a Housing First program can assess survivors' experience with financial abuse and can provide interventions aimed at improving survivors' financial literacy and increasing economic self-sufficiency, which are both associated with economic empowerment (Postmus, Plummer, McMahon, \& Zurlo, 2013). The experience of financial abuse may be different for immigrant women who have additional barriers to work due to language, documentation status, and oppression (Ayon, Messing, Gurrola, \& Valencia-Garcia, in press). Thus, cultural competency, which is necessary to understand IPV from the perspective of a survivor with a marginalized identity, is central to the trauma-informed care approach and should be explored in future research.

A trauma-informed care approach is more than providing trauma-informed care services for clients; it means having a trauma-informed care approach for practitioners as well. Social work practice with survivors of IPV is emotional work and practitioners risk burnout and secondary traumatic stress (Powell-Williams, White, \& Powell-Williams, 2013; Strand et al., 2013). Similar to previous research (Slattery \& Goodman, 2009; Strand et al., 2013), practitioners highlighted the positive impact of the agency's supportive culture and prioritization of self-care for practitioners individually and as a team. Using a trauma-informed care model in services not only benefits clients but can also increase worker satisfaction (Kulkarni, Bell, \& Rhodes, 2012).

A Housing First model combined with a trauma-informed care approach has the potential to increase worker satisfaction by providing workers with flexibility and mobility to meet with survivors in their community (Mbilinyi, 2015). IPV practitioners have 
reported frustration and a lack of feeling successful in their jobs when survivors return to their abuser (Powell-Williams et al., 2013). Permanent, safe housing that allows women to remain free from their abuser may have the added benefit of increasing job satisfaction for practitioners (Mbilinyi, 2015). Returning to an abusive partner was not reported among clients in this program. Longitudinal research to examine the sustainability of housing and survivors' relationship status after completion of Housing First programs in domestic violence agencies is needed.

\section{Strengths and Limitations}

This research examines the intersection of trauma-informed care in a Housing First model for IPV survivors. Our analysis is limited due to the focus on a single program within a single agency; although the agency has other programs (i.e., shelter, community based services), those were not the focus of this inquiry. This limitation is offset by the strength of the case study design which allows an in-depth examination of a unique intervention for IPV survivors. Additionally, the use of multiple forms of data in the analysis adds to the rigor of the study, including the dual perspective that was offered by data collected from both practitioners and administrators. Because this is based primarily on workers' perspectives, we do not know if the clients would report the same. Workers may also feel compelled to speak positively of their organization in an effort to highlight the good in their program, a form of respondent bias (Padgett, 2008).

A major limitation of this study is the methods that the agency uses to evaluate client outcomes. The data were not available in their raw form. Thus, we did not know response rates, whether clients took the surveys multiple times over multiple quarters, how long clients completing the surveys had been receiving services, or which phase of the program the clients were in when they completed the survey. The race/ethnicity of survivors who completed the surveys is unknown as well as whether the survey was completed in languages other than English. When examining agencies that are providing innovative services, ideally researchers would have collected both qualitative and quantitative data directly from the clients receiving services from that agency.

\section{Suggestions for Future Research}

Additional research with this agency and with agencies providing services to survivors of IPV through a Housing First model is needed. In particular, researchers need to continue to explore how trauma-informed care and Housing First models impact worker satisfaction, burnout, and secondary traumatic stress. Additionally, future research should include longitudinal, quantitative studies examining both survivor and child outcomes related to housing, trauma symptomatology, and survivor-defined services. Future research should also connect forms of abuse, risk, coping, and trauma with specific outcomes to understand for whom Housing First services are most appropriate. Research examining trauma informed care approaches in other IPV service settings is also of import to understand the intersection of trauma informed care approaches with more traditional IPV services (residential settings, for example). 


\section{References}

Allen, N. E., Bybee, D. I., \& Sullivan, C. M. (2004). Battered women's multitude of needs: Evidence supporting the need for comprehensive advocacy. Violence Against Women, 10(9), 1015-1035. doi: https://doi.org/10.1177/1077801204267658

Arnold, G., \& Ake, J. (2013). Reframing the narrative of the battered women's movement. Violence Against Women, 19(5), 557-578. doi: https://doi.org/10.1177/1077801213490508

Ayón, C., Messing, J. T., Gurrola, M., \& Valencia-Garcia, D. (in press). The oppression of Latina mothers: Experiences of exploitation, violence, marginalization, cultural imperialism and powerlessness in their everyday lives. Violence Against Women.

Baker, C. K., Billhardt, K. A., Warren, J., Rollins, C., \& Glass, N. E. (2010). Domestic violence, housing instability, and homelessness: A review of housing policies and program practices for meeting the needs of survivors. Aggressive and Violent Behavior, 15, 430-439. doi: https://doi.org/10.1016/j.avb.2010.07.005

Black, M. C., Basile, K. C., Breiding, M. J., Smith, S. G., Walters, M. L., Merrick, M., ...Stevens, M. R. (2011). The National Intimate Partner and Sexual Violence Survey (NISVS): 2010 Summary Report. Atlanta, GA: National Center for Injury Prevention and Control, Centers for Disease Control and Prevention.

Campbell, J. C. (2003). The Danger Assessment. Retrieved from https://www.dangerassessment.org/uploads/pdf/DAEnglish2010.pdf

Campbell, J. C., Glass, N., Sharps, P. W., Laughon, K., \& Bloom, T. (2007). Intimate partner homicide: Review and implications of research and policy. Trauma, Violence, \& Abuse, 8(3), 246-269. doi: https://doi.org/10.1177/1524838007303505

Culhane, D. P., Gross, K. S., Parker, W. D., Poppe, B., \& Sykes, E. (2008). Accountability, cost-effectiveness, and program performance: Progress since 1998. Retrieved from http://repository.upenn.edu/cgi/viewcontent.cgi?article=1116\&context=spp_papers

Dedoose Version 7.0.23, web application for managing, analyzing, and presenting qualitative and mixed method research data (2016). Los Angeles, CA: SocioCultural Research Consultants, LLC. Retrieved from www.dedoose.com

Dichter, M. E., \& Rhodes, K. V. (2011). Intimate partner violence survivors' unmet social service needs. Journal of Social Service Research, 37, 481-489. doi: https://doi.org/10.1080/01488376.2011.587747

Elliott, D. E., Bjelajac, P., Fallot, R. D., Markoff, L. S., \& Reed, B. G. (2005). Traumainformed or trauma-denied: Principles and implementation of trauma-informed services for women. Journal of Community Psychology, 33(4), 461-477. doi: https://doi.org/10.1002/jcop.20063 
Kulkarni, S. J., Bell, H., \& Rhodes, D. M. (2012). Back to basics: Essential qualities of services for survivors of intimate partner violence. Violence Against Women, 18(1), 85-101. https://doi.org/10.1177/1077801212437137

Macy, R. J., Giattina, M. C., Montijo, N. J., \& Ermentrout, D. M. (2010). Domestic violence and sexual assault agency directors' perspectives on services that help survivors. Violence Against Women, 16(10), 1138-1161. doi: https://doi.org/10.1177/1077801210383085

Mbilinyi, L. (2015). The Washington state domestic violence Housing First program: Cohort 2 agencies final evaluation report September 2011 - September 2014. Retrieved from http://wscadv2.org/docs/DVHF-FinalEvaluation.pdf

McDermott, M. J., \& Garofalo, J. (2004). When advocacy for domestic violence backfires: Types and sources of victim disempowerment. Violence Against Women, 10(11), 1245-1266. doi: https://doi.org/10.1177/1077801204268999

Messing, J. T., O’Sullivan, C., Cavanaugh, C. E., \& Campbell, J. C. (2016). Are abused women's protective actions associated with reduced threats, stalking, and violence perpetrated by their male intimate partners? Violence Against Women, 23(3), 263286.

Messing, J. T., \& Thaller, J. (2015). Intimate partner violence risk assessment: A primer for social workers. British Journal of Social Work, 45(6), 1804-1820. doi: https://doi.org/10.1093/bjsw/bcu012

Messing, J. T., Ward-Lasher, A., Thaller, J., \& Bagwell-Gray, M. (2015). The state of intimate partner violence intervention: Progress and continuing challenges. Social Work, 60(4), 305-313. doi: https://doi.org/10.1093/sw/swv027

Montgomery, A. E., Hill, L. L., Kane, V., \& Culhane, D. P. (2013). Housing chronically homeless veterans: Evaluating the efficacy of a housing first approach to HUDVASH. Journal of Community Psychology, 41(4), 505-514. doi: https://doi.org/10.1002/jcop.21554

OrgCode Consulting. (2017). SPDAT. Retrieved from http://orgcode.nationbuilder.com/spdat

Padgett, D. K. (2016). Qualitative methods in social work research ( $2^{\text {nd }}$ ed.). UK: Sage.

Padgett, D., Henwood, B. F., \& Tsemberis, S. J. (2015). Housing first: Ending homelessness, transforming systems, and changing lives. Oxford, NY: Oxford University Press.

Patterson, M., Moniruzzaman, A., Palepu, A., Zabkiewicz, D., Frankish, C. J., Krausz, M., \& Somers, J. M. (2013). Housing First improves subjective quality of life among homeless adults with mental illness: 12-month findings from a randomized control trial in Vancouver, British Columbia., Social Psychiatry and Psychiatric Epidemiology, 48, 1245-1259. doi: https://doi.org/10.1007/s00127-013-0719-6 
Pavao, J., Alvarez, J., Baumrind, N., Induni, M., \& Kimerling, R. (2007). Intimate partner violence and housing instability. American Journal of Preventive Medicine, 32(2), 143-146. doi: https://doi.org/10.1016/j.amepre.2006.10.008

Postmus, J. L., Plummer, S. B., McMahon, S., Murshid, N. S., \& Kim, M. S. (2012). Understanding economic abuse in the lives of survivors. Journal of Interpersonal Violence, 27(3), 411-430. doi: https://doi.org/10.1177/0886260511421669

Postmus, J. L., Plummer, S. B., McMahon, S., \& Zurlo, K. A. (2013). Financial literacy: Building economic empowerment with survivors of violence. Journal of Family and Economic Issues, 34(3), 275-284. doi: https://doi.org/10.1007/s10834-012-9330-3

Powell-Williams, M., White, S. D., \& Powell-Williams, T. (2013). "I help the ones that want help": Emotion work and the victim advocate role. Sociological Spectrum, 33, 258-275. doi: https://doi.org/10.1080/02732173.2013.732904

Richmond, M. K., Pampel, F. C., Zarcula, F., Howey, V., \& McChesney, B. (2015). Reliability of the Colorado Family Support Assessment: A Self-Sufficiency Matrix for Families. Research on Social Work Practice, 2015, 1-9. doi: https://doi.org/10.1177/1049731515596072

Schiff, J. W., \& Schiff, R. A. (2014). Housing first: Paradigm or program? Journal of Social Distress and the Homeless, 23(2), 80-104. doi: https://doi.org/10.1179/1573658X14Y.0000000007

Slattery, S. M., \& Goodman, L. A. (2009). Secondary traumatic stress among domestic violence advocates: Workplace risk and protective factors. Violence Against Women, 15(11), 1358-1379. doi: https://doi.org/10.1177/1077801209347469

Stark, E. (2007). Coercive control: How men entrap women in personal life. New York: Oxford University Press.

Strand, V. C., Hansen, S., \& Courtney, D. (2013). Common elements across evidencebased trauma treatment: Discovery and implications. Advances in Social Work, 14(2), 334-354.

Sullivan, C. M., Basta, J., Tan, C., \& Davidson, W. S., II. (1992). After the crisis: A needs assessment of women leaving a domestic violence shelter. Violence \& Victims, $7(3), 267-275$.

Thomas, K. A., Goodman, L., \& Putnins, S. (2015). "I have lost everything": Trade-offs of seeking safety from intimate partner violence. American Journal of Orthopsychiatry, 85(2), 170-180. doi: https://doi.org/10.1037/ort0000044

Tsemberis, S., Gulcur, L., \& Nakae, M. (2004). Housing First, consumer choice, and harm reduction for homeless individuals with a dual diagnosis. American Journal of Public Health, 94(4), 651-656. doi: https://doi.org/10.2105/AJPH.94.4.651

Wilson, J. M., Fauci, J. E., \& Goodman, L. A. (2015). Bringing trauma-informed practice to domestic violence programs: A qualitative analysis of current approaches. 
American Journal of Orthopsychiatry, 85(6), 586-599. doi:

https://doi.org/10.1037/ort0000098

Yin, R. K. (2014). Case study research: Design and methods. Los Angeles, CA: Sage.

Author note: Address correspondence to: Allison Ward-Lasher, School of Social Work, Arizona State University, 411 N. Central Ave, Phoenix, AZ 85004, 602-639-1536, allison.ward@asu.edu 